\title{
Influence of Lignocellulose Fillers on Properties Natural Rubber Composites
}

\author{
Przemysław Rybiński ${ }^{1}$ (I) Bartłomiej Syrek ${ }^{1} \cdot$ Marcin Masłowski ${ }^{2} \cdot$ Justyna Miedzianowska $^{2} \cdot$ Krzysztof Strzelec $^{2}$. \\ Witold Żukowski ${ }^{3}$. Dariusz Bradło ${ }^{3}$
}

Published online: 17 November 2017

(c) The Author(s) 2017. This article is an open access publication

\begin{abstract}
The present article presents unreported yet in the subject literature examinations of the effect of a lignocellulose filler obtained from an alkalized wheat straw treated with di-potassium phosphate on the properties of natural rubber composites. The thermal and mechanical properties as well as the fire hazard of the composites obtained were tested also in the presence of an additive flame-retardant compound (poly(ammonium phosphate)), exploiting the synergism of its action with pentaerythritol, antimony trioxide, aluminum hydroxide and zinc borate. Based on the results obtained by the methods of thermal and mechanical analyses, micro-calorimetry and cone calorimetry, it has been found that the bio-filler increases, especially in the presence of additive flame-retardant, the resistance of the bio-composites tested to the action of fire, without a significant deterioration in their mechanical properties.
\end{abstract}

Keywords Natural rubber $\cdot$ Lignocellulose $\cdot$ Flammability $\cdot$ Thermal properties $\cdot$ Mechanical properties

\section{Introduction}

In recent years one could observe the use of elastomeric bio-composites in many industrial branches, especially in the construction industry and motor transport.

However, the use of natural fibers (lignocellulose) as rubber fillers gives rise to many technological problems. On the one hand, they are light and derived from renewable sources, and consequently are commonly accessible and relatively cheap, on the other hand they show a low compatibility in relation to an elastomeric matrix. Natural fibers also constitute an excellent fuel source, which drastically increases the fire hazard created by the composites filled with them. The precondition for an effective use of lignocellulose raw materials is an increase in their adhesion to the polymeric matrix,

Przemysław Rybiński

przemyslaw.rybinski@ujk.kielce.pl

1 Department of Management and Environmental Protection, Jan Kochanowski University, Kielce, Poland

2 Faculty of Chemistry, Institute of Polymer and Dye Technology, Lodz University of Technology, Łodź, Poland

3 Faculty of Chemical Engineering and Technology, Cracow University of Technology, Cracow, Poland resulting in an improvement in the mechanical properties of the composites filled with them.

A increase in the interfacial (fiber-polymer) interactions can be obtained by the chemical modification of fibers. From the review of source literature it follows that the alkalization of natural fibers is a relatively easy and cheap method of their modification [1].

The alkalization of natural fibers is based on the same principles as those of the process of cotton mercerization. Natural fibers are subjected to the action of an alkaline solution, e.g. $\mathrm{NaOH}$ that changes the fiber properties. Initially, the alkalization process was used to bleach these fibers and to impart a luster to them, while recent literature reports distinctly indicate a positive effect of this process on the properties of polymeric composites containing such fibers [2,3].

The basic component of natural fiber is cellulose, occurring in the form of crystal lattice (cellulose-I) that can be transformed by chemical processes into other polymorphic varieties, among which alkali-cellulose and cellulose-II are of the greatest importance [1, 4].

The action of alkaline compounds on cellulose fibber results in fiber swelling that leads to loosening the cellulose crystalline lattice. The swelling degree of cellulose and its transformation to cellulose-II can be different depending on the type of alkaline compound $(\mathrm{KOH}, \mathrm{LiOH}, \mathrm{NaOH})$ and 
also on its concentration. Currently, it is known that sodium ions have optimal dimensions to get in the crystalline lattice micro-pores, which causes that under the influence of sodium hydroxide cellulose obtains the highest degree of swelling. Once the excess of $\mathrm{NaOH}$ is removed, there is formed a new crystalline structure (Na-cellulose) with relatively great distances between molecules filled with water, in which hydroxyl groups $(-\mathrm{OH})$ have been replace with $-\mathrm{ONa}$ groups. The evaporation of water causes a simultaneous removal of sodium ions, resulting in the transformation of Na-cellulose into cellulose-II [1].

The crystalline structure of cellulose II is thermodynamically more stable than that of cellulose I, what is more, even with low $\mathrm{NaOH}$ concentrations, lingo-cellulose fibers undergo fibrillation resulting in the reduction in their diameter. As a result, the shape coefficient increases and consequently the effective area of the fiber being in contact with the polymeric matrix. Together with the porous fiber surface, this results in a decisive increase in the adhesive interactions of the fiber-polymeric matrix system [5].

From the point of view of using lignin-cellulose raw materials as polymer bio-fillers, it is a key issue to radically reduce their flammability.

From the literature review it follows that the flammability of natural fibers depends of their chemical composition. Even a low quantity of lignin (10\%) increases the resistance of natural fibers to fire [6]. Studies carried out by Kozlowski and co-workers have shown that lignin-rich natural fibers (flux, hemp) are characterized by a lower rate of emitted heat than the fibers with high cellulose content. This is the way, the lignin capability to catalyze carbonization processes is shown. These processes positively influence the formation of an insulating carbon layer that increases the fire resistance of elastomeric bio-composites [7, 8]. An increase in the carbonization efficiency during the decomposition of natural fibers can be obtained by modifying the fibers by means of appropriate flame-retardant compounds such as ammonium salts of phosphoric acid, boric acid, zinc borate, zinc chloride, salts of sulfuric acid, magnesium and aluminum hydroxides or expandable graphite.

The modification of natural fibers by means of flameretardant compounds can proceed according to the following procedures: fiber impregnation with the use of flame-retardant solution, deposition of flame-retardant compound on the fiber surface modified by means of an adhesive-improving substance (mostly a condensation product of formaldehyde and melamine urea and plant protein) or by a simple mixing natural fibers with flame-retardant compound before their incorporation into the polymeric matrix [9-11].

The subject literature offers a few reports concerning the reduction in the natural fibers flammability. For example, Kondola and Horrocks have modified cellulose (viscose) as well as a cellulose woven fabric with the use of both melamine and phosphoric flame-retardants. Based on the tests performed, they have found that a considerable quantity of carbon formed above $500{ }^{\circ} \mathrm{C}$ distinctly improves the thermal properties of fibers modified in this way, as confirmed by an increase in the activation energy of destruction, "Ea", and a reduction in heat conduction [12]. Flambard and co-workers have reduced the flammability of flux and wool fibers, designed for the production of woven fabrics to be used in public transport, mixing them with poly(pphenylenediamineterephthalamide) (PPTA). The modified fibers were characterized not only by a high resistance to fire but also resistance to UV radiation, satisfactory mechanical properties, biodegradability and easy processing [13].

Suardana and co-workers modified coconut and jute fibers with the use of diammonium phosphate (DAP), and then the fibers were incorporated into the matrix of a thermoplastic polymer. Based on the tests performed, they have found that the improvement in bio-composite resistance to fire is directly proportional to the quantity of DAP used for the fiber modification, which directly results from the quantity of carbonized residue formed above $500{ }^{\circ} \mathrm{C}$ [14].

Shumao and co-workers have shown that a considerable increase in the fiber resistance to the action of fire can be obtained the modification of fiber surface with poly(ammonium phosphate) (PAP) as well as by a direct incorporation of this flame-retardant into the polymer matrix (PLA) [15].

The present article presents unreported yet in the subject literature examinations of the effect of a lignocellulose filler obtained from an alkalized wheat straw treated with di-potassium phosphate on the properties of natural rubber composites. The thermal and mechanical properties as well as the fire hazard of the composites obtained were tested also in the presence of an additive flame-retardant compound (poly(ammonium phosphate)), exploiting the synergism of its action with pentaerythritol, antimony trioxide, aluminum hydroxide and zinc borate.

\section{Experimental}

\section{Materials}

\section{Rubber}

The object of study was natural rubber (NR) RSSI, cis1,4-polyisoprene, density $0.93-0.988 \mathrm{~g} / \mathrm{cm}^{3}$, from Torimex Chemicals. The rubber was cross-linked by means of sulfur in the presence of zinc oxide and 2-mercaptobenzothiazole (MBT) and steric acid. 


\section{Fillers}

Bio-Filler Alkalization of straw: Wheat straws was collected from local farms. Lignocellulose materials was treated using $10 \%$ solution of sodium hydroxide. The straw was soaked in the sodium hydroxide solution for $48 \mathrm{~h}$ at room temperature. Afterwards, the straw was drained, and then continuously washed with tap water, removing any $\mathrm{NaOH}$ solution. Finally, the materials were dried at room temperature until a constant weight was reached. Dried treatment straw was ground into fine powder using a ball mill (SPEX SamplePrep 8000D Mixer/Mill).

Phosphorylation of straw: The alkaline straw was immersed in the water solution of potassium dihydrogen phosphate $\left(\mathrm{KH}_{2} \mathrm{PO}_{4}\right)$ with concentration $15 \mathrm{wt} \%$ of $\mathrm{KH}_{2} \mathrm{PO}_{4}$. The ratio of straw to potassium dihydrogen phosphate solution was $20 \mathrm{~g}$ straw to $100 \mathrm{ml}$ solution. The mixture was than heated in an water bath at $65^{\circ} \mathrm{C}$ for $30 \mathrm{~min}$. After heating, the straw was removed from the solution and directly dried in the oven at $70{ }^{\circ} \mathrm{C}$ for the constant mass.

\section{Flame Retardants}

APP (ammonium polyphosphate), phosphorus content 31-32\%, nitrogen content 14-15\%; ZB (zinc borate), boron oxide content $47-49 \%$, zinc oxide content $37-40 \%, \mathrm{Sb}_{2} \mathrm{O}_{3}$ (antimony trioxide), purity 99.8\% were purchased from Everkem. ATH (aluminum hydroxide) was originated from POCH Gliwice. PER (pentaerythritol) was purchased from Perstorp.

\section{Methods}

\section{Preparation of Rubber Samples}

Rubber blends were prepared using a laboratory two-roll mill, with roll dimensions of $\mathrm{D}=140 \mathrm{~mm}$ and $\mathrm{L}=300 \mathrm{~mm}$. The average temperature of the rolls was $35^{\circ} \mathrm{C}$. The rotational speed of the front roll was $\mathrm{V}_{\mathrm{p}}=20 \mathrm{rpm}$, friction $1: 1$.

The composition of the rubber mixtures are shown in Table 1.

Kinetic parameters of vulcanization of the elastomer blends were measured by means of MonTech DRPA 300 Rheometer, at $160{ }^{\circ} \mathrm{C}$, according to standard PN-ISO $3417: 1994$, directly after the preparation of the rubber blends, and for comparison, after a week of conditioning at the ambient temperature. The blends were vulcanized in steel moulds placed between electrically heated press shelves.

\section{Experimental Techniques}

SEM Imaging Microscopic photographs of the bio-filler were obtained by means of a Hitachi TM3000 scanning electron microscope (SEM).

Determination of Cross-Link Density Equilibrium swelling method was used to determine the cross-link density of the vulcanizates. Samples were swollen in the toluene at the temperature $\mathrm{T}=25{ }^{\circ} \mathrm{C}$ for $48 \mathrm{~h}$ and then removed from the solvent and the surface toluene was quickly blotted off. The samples were immediately weighed and then dried in a

Table 1 Composition of the NR rubber-based mixtures

\begin{tabular}{|c|c|c|c|c|c|c|c|c|}
\hline \multirow[t]{2}{*}{ Component (phr) } & \multicolumn{8}{|c|}{ Sample description } \\
\hline & NR & $\mathrm{NR}-\mathrm{C}(\mathrm{OH})$ & $\mathrm{NR}-\mathrm{C}(\mathrm{P})$ & $\mathrm{NR}-\mathrm{C}(\mathrm{P})-\mathrm{APP}$ & $\begin{array}{l}\text { NR-C(P)- } \\
\text { APP-PER }\end{array}$ & $\begin{array}{l}\mathrm{NR}-\mathrm{C}(\mathrm{P})- \\
\mathrm{APP}-\mathrm{Sb}_{2} \mathrm{O}_{3}\end{array}$ & $\begin{array}{l}\text { NR-C(P)- } \\
\text { APP-ATH }\end{array}$ & $\begin{array}{l}\mathrm{NR}- \\
\mathrm{C}(\mathrm{P})- \\
\mathrm{APP}-\mathrm{ZB}\end{array}$ \\
\hline NR rubber & 100 & 100 & 100 & 100 & 100 & 100 & 100 & 100 \\
\hline Zinc oxide & 5 & 5 & 5 & 5 & 5 & 5 & 5 & 5 \\
\hline Stearic acid & 1 & 1 & 1 & 1 & 1 & 1 & 1 & 1 \\
\hline MBT & 2 & 2 & 2 & 2 & 2 & 2 & 2 & 2 \\
\hline$S$ & 2 & 2 & 2 & 2 & 2 & 2 & 2 & 2 \\
\hline $\mathrm{C}(\mathrm{OH})$ & - & 30 & - & - & - & - & - & - \\
\hline $\mathrm{C}(\mathrm{P})$ & - & - & 30 & 30 & 30 & 30 & 30 & 30 \\
\hline APP & - & - & - & 30 & 30 & 30 & 30 & 30 \\
\hline PER & - & - & - & - & 10 & - & - & - \\
\hline $\mathrm{Sb}_{2} \mathrm{O}_{3}$ & - & - & - & - & - & 10 & - & - \\
\hline ATH & - & - & - & - & - & - & 40 & - \\
\hline $\mathrm{ZB}$ & - & - & - & - & - & - & - & 30 \\
\hline
\end{tabular}

$M B T$ 2-mercaptobenzothiazole, $S$ sulfur, $C(O H)$ alkaline wheat straw, $C(P)$ phosphorylated alkaline wheat straw, $A P P$ ammonium polyphosphate, $P E R$ pentaerythritol, $\mathrm{Sb}_{2} \mathrm{O}_{3}$ antimony trioxide, $\mathrm{ATH}$ aluminum hydroxide, $\mathrm{ZB}$ zinc borate 
vacuum oven for $36 \mathrm{~h}$ at $80{ }^{\circ} \mathrm{C}$ to remove all the solvent and reweighed.

The value of equilibrium swelling was calculated by the following equation:

$Q_{w}=\frac{m_{s p}-m_{s}}{m_{s}^{*}}$

where $\mathrm{Q}_{\mathrm{w}}$ is the equilibrium swelling, $\mathrm{m}_{\mathrm{sp}}$ is the mass of swelled sample $(\mathrm{mg}), \mathrm{m}_{\mathrm{s}}$ is the mass of dried sample after swelling $(\mathrm{mg}), \mathrm{m}_{\mathrm{s}}{ }^{*}$ is the mass of dried sample after swelling, corrected with the contribution of mineral substances (mg).

$m_{s}^{*}=m_{s}-m_{o}\left(m_{n} / m_{c}\right)$

where $m_{o}$ is the initial mass of sample $(\mathrm{mg}), \mathrm{m}_{\mathrm{n}}$ is the mass of mineral substances contained in the blend $(\mathrm{mg}), \mathrm{m}_{\mathrm{c}}$ is the mass of all blend components (mg).

The degree of cross-linking $\alpha_{C}$, was calculated by the following equation:

$\alpha_{c}=\frac{1}{Q_{w}}$

The result of equilibrium swelling was an arithmetical average of four determinations.

Equilibrium volumetric swelling Qv, determined from the equation:

$Q_{v}=Q_{w} \times\left(\frac{d_{k}}{d_{r}}\right)$

where $d_{k}$ is the rubber density in vulcanizate $\left(\mathrm{g} \mathrm{cm}^{-3}\right), d_{r}$ is the solvent density. Density of toluene is $0.866\left(\mathrm{~g} \mathrm{~cm}^{-3}\right)$.

The elastically active network chain $\nu$, which was used to represent the whole cross-link density, was then calculated by the well-known Flory-Rehner equation [16-18]:

$V_{r}=1 /\left(1+Q_{v}\right)$

$\nu=-\frac{\ln \left(1-V_{r}\right)+V_{r}+\mu V_{r}^{2}}{V_{0}\left(V_{r}^{\frac{1}{3}}-\frac{2 V_{r}}{f}\right)}$

where $v$ is the concentration of effective chains $\left(\mathrm{mol} \mathrm{cm}^{-3}\right)$, $\mathrm{V}_{\mathrm{r}}$ is the the volume fraction of the polymer in the vulcanizate swollen to equilibrium, $\mathrm{V}_{0}$ is the solvent molar volume (for toluene $\mathrm{V}_{\mathrm{s}}=107 \mathrm{~cm}^{3} \mathrm{~mol}^{-1}$ ), $\mathrm{f}$ is the functionality of network, $\mu$ is the Huggins parameter of the interactions between cross-linked rubber and solvent being a linear function of cross-link density $\mathrm{Vr}, \mu=\mu_{0}+\beta \mathrm{V}_{\mathrm{r}}$. Elastomersolvent interaction $\mu_{0}$ and $\beta$ were determined experimentally $\mu_{0}=0.478, \beta=0.228$.
Oil Absorption The oil absorption parameter (DBPA) of fillers was measured according to ASTM D2414 using Absorptometer C (Brabender). Process parameters: sample weight $20 \mathrm{~g}$, titration rate $4.0 \mathrm{ml} / \mathrm{min}$. The oil used in this study was dibutyl phthalate DBP.

FTIR Analysis Fourier transform infrared (FTIR) spectra were recorded on a FTIR Nicolet 6700 spectrophotometer and OMNIC 3.2 software (Thermo Scientific Products: Riviera Beach, FL, USA) at room temperature. Attenuated total reflection (ATR) accessory equipped with a single reflection diamond ATR crystal on ZnSe plate was used for all of the analysis. Fourier transform infrared spectroscopy was performed with a DGTS/KBr detector. Measurement parameters: 128 scans signal from 500 to $4000 \mathrm{~cm}^{-1}$ in absorbance mode with resolution $8 \mathrm{~cm}^{-1}$ and the speed of scanning equal to $0.6329 \mathrm{~cm} \mathrm{~s}^{-1}$.

Bio-Fillers Flammability Flammability of wheat straw were examined by means of the FAA micro-calorimeter from Fire Testing Technology Limited. The temperature of the pyrolyser was $600{ }^{\circ} \mathrm{C}$, while that of combustor $900{ }^{\circ} \mathrm{C}$. During measurement the following parameters were recorded: ignition temperature $\left(\mathrm{T}_{\mathrm{z}}\right)$, maximum heat emission rate $\left(\mathrm{HRR}_{\max }\right)$, total heat emitted (HR), heat capacity, and percentage oxygen consumption. The sample was heated using a linear temperature program, and the volatile thermal degradation products were swept from the pyrolysis chamber by an inert gas and combined with excess oxygen in a tubular furnace at the temperature of $900{ }^{\circ} \mathrm{C}$ to force complete combustion (oxidation) of the fuel. Combustion products $\mathrm{CO}_{2}$, $\mathrm{H}_{2} \mathrm{O}$, and acid gases were scrubbed from the gas stream and the transient heat release rate was calculated from the measured flow rate and oxygen concentration after correcting for flow dispersion. The maximum (peak) value of the PCFC heat release rate normalized for the initial sample mass and heating rate was a material flammability parameter with units of heat release capacity $(\mathrm{J} / \mathrm{g}-\mathrm{K})$ which depends only on chemical composition of the sample and is proportional to the burning rate of the material in a fire.

NR Composites Flammability The NR composites were examined using a cone calorimeter from Fire Testing Technology Ltd. Elastomer samples with dimensions of $(100 \times 100 \pm 1) \mathrm{mm}$ and thickness of $(2 \pm 0.5) \mathrm{mm}$ were tested in a horizontal position with a heat radiant flux density of $35 \mathrm{~kW} \mathrm{~m}{ }^{-2}$. During the tests, the following parameters were recorded: initial sample weight; time to ignition (TTI); sample weight during testing; total heat released (THR); effective combustion heat (EHC); average weight loss rate (MLR); heat release rate (HRR); final sample weight. 
Thermal Properties The thermal properties of the rubber composites were tested under air atmosphere at temperatures ranging from 25 to $700{ }^{\circ} \mathrm{C}$ with the use of a thermal analyser (Jupiter STA 449F3, Netzsch Company). Weighed portions of 5-10 mg of sample were analysed at a heating rate of $10{ }^{\circ} \mathrm{C} \mathrm{min}^{-1}$.

Mechanical Properties The mechanical properties [the modulus at $300 \%$ elongation $\left(\mathrm{SE}_{300}\right)$, tensile strength (TS) and elongation at break (EB)] of vulcanizates was characterized according to standard PN-ISO 37:1998 by means of a ZWICK tensile testing machine, model 1435 from the Zwick Roell Group (Ulm, Germany) for dumbbell w-3. Five different dumbbell shaped specimens were tested, and the average value for each formulation was reported.

Dynamic measurements in tension were carried out using a ARES Rheometer (plate-plate system, plate diameter: $20 \mathrm{~mm}$; gap $2 \mathrm{~mm}$ ). The shear testing parameters: temperature: $25^{\circ} \mathrm{C}$, sample deformation rate: $10 \mathrm{rad} / \mathrm{s}$, stress: from 0.1 to $150 \%$, test force: $5 \mathrm{~N}$. The Payne effect ( $\left.\Delta \mathrm{G}^{\prime}[\mathrm{MPa}]\right)$ values of the composites have been calculated based on the following equation.

$\Delta \mathrm{G}^{\prime}=\mathrm{G}_{\text {min }}^{\prime}\left(\lim 10^{-1}\right)-\mathrm{G}_{\text {max }}^{\prime}(\infty)$

where $\mathrm{G}_{\min }^{\prime}\left(\lim 10^{-1}\right)$ is a composite storage modulus determined under the deformation of $10^{-1} \%$; $\mathrm{G}_{\max }^{\prime}(\infty)$ is a composite storage modulus determined under the max deformation.

\section{Results}

\section{Characteristic of Lignocellulose Fillers}

\section{SEM Analysis}

Figure 1 shows SEM images of wheat straw in three versions: unmodified $\mathrm{C}(\mathrm{N})$, hydrolytically modified $\mathrm{C}(\mathrm{OH})$ and phosphorylated $\mathrm{C}(\mathrm{P})$ wheat straw. Based on the analysis of the SEM pictures obtained, one can conclude that the phosphorylation process does not fundamentally affect the appearance of fiber surface, nevertheless under the influence of phosphorylation the fiber surface is distinctly smoothed (Fig. 1). The phosphorus content in the modified, determined by the EDS technique amounts to $1.44 \%$ wag (Table 2).

\section{The Oil Absorption of Wheat Straw}

The dibutyl-phthalate oil absorption (DBPA) is used to measure structure and porosity of the filler particles. The results of DBPA oil absorption values are given in the Fig. 2. The used bio-fillers are characterized by similar structure, that reflects in the value of DBPA in the range of $140-150 \mathrm{ml} / 100 \mathrm{~g}$ of filler.

\section{FTIR Analysis}

FTIR spectra of wheat straws: unmodified $\mathrm{C}(\mathrm{N})$, hydrolytically modified $\mathrm{C}(\mathrm{OH})$ and phosphorylate $\mathrm{C}(\mathrm{P})$ distinctly differ from each other. At wavelength $3000-3600 \mathrm{~cm}^{-1}$ there appears a signal connected with stretching vibration of $\mathrm{OH}$ group located firstly in cellulose but also in lignin or hemicellulose. As a result of alkalization and phosphorylation of the bio-filler, the intensity of this signal decreases, which is connected with breaking hydrogen bonds between $\mathrm{OH}$ groups in the cellulose molecules (Fig. 3).
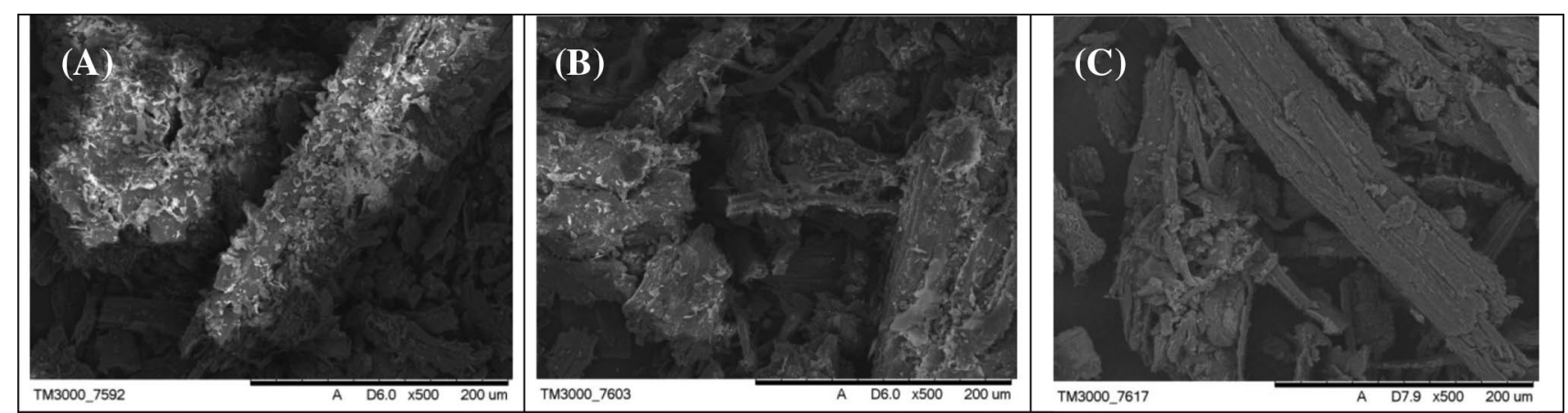

Fig. 1 a Unmodified wheat straw $\mathrm{C}(\mathrm{N})$, b hydrolytically modified wheat straw $\mathrm{C}(\mathrm{OH})$, $\mathbf{c}$ phosphorylated wheat straw $\mathrm{C}(\mathrm{P})$ 

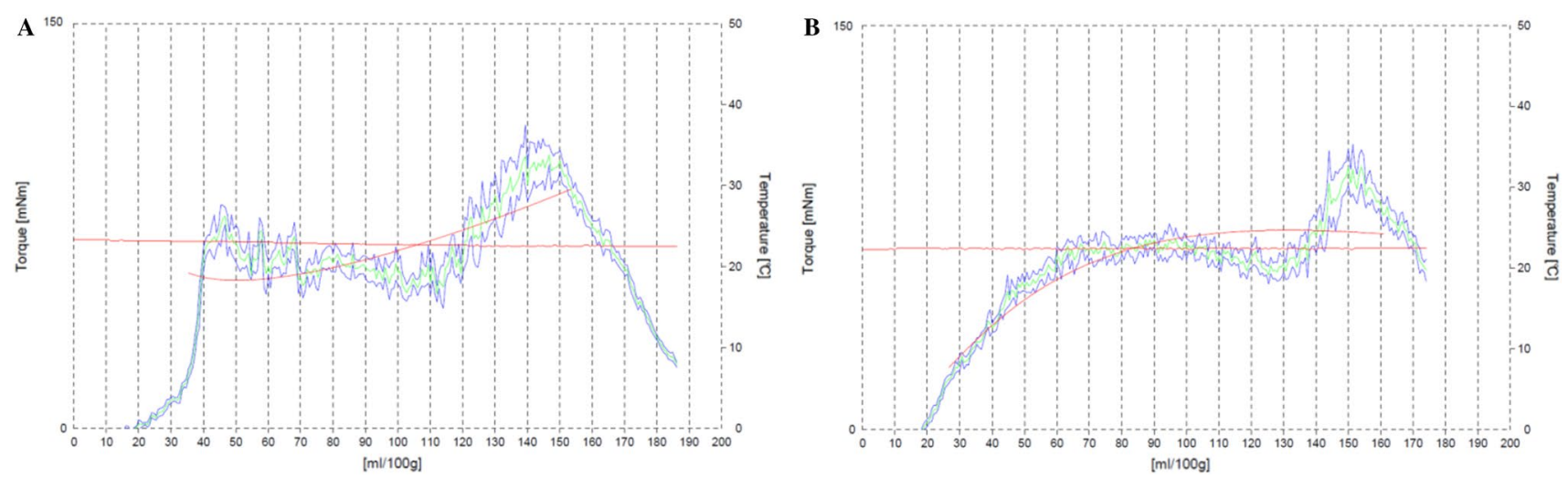

Fig. 2 The oil absorption of bio-filler. a Alkalized wheat straw, b phosphated wheat straw

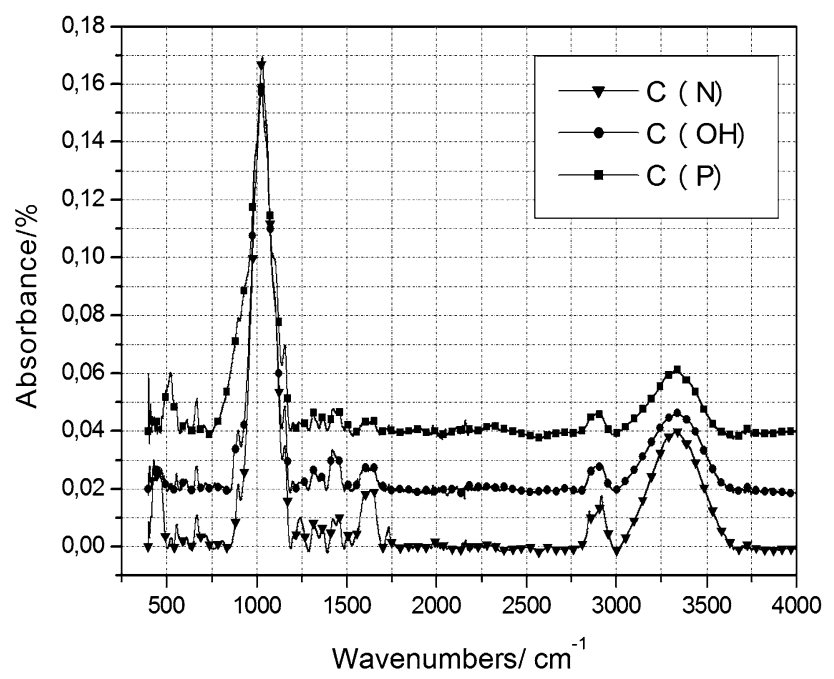

Fig. 3 FTIR spectra of unmodified bio-filler $\mathrm{C}(\mathrm{N})$, subjected to hydrolysis $\mathrm{C}(\mathrm{OH})$ and phosphorylation $\mathrm{C}(\mathrm{P})$

The signal within the wavelength of 2800-2950 corresponds to the stretching vibration of methylene group $-\mathrm{CH}_{2}$ and methyl group $-\mathrm{CH}_{3}$. The peak at a wavelength of $1730 \mathrm{~cm}^{-1}$ is connected with the stretching vibration of group $\mathrm{C}=\mathrm{O}$, derived from the acetyl group of hemi-cellulose. This signal is not recorded in the FTIR spectrum of the biofiller subjected to alkalization and phosphorylation, which indicates a partial removal of hemi-cellulose from the structure of the bio-filler. The disappearance of signals at wavelengths $1245-1259 \mathrm{~cm}^{-1}$ also indicates a partial removal hemi-cellulose from the structure of bio-filler after hydrolysis. The spectrum of the bio-filler subjected to hydrolysis shows no signals at wavelengths 1464 and $1376 \mathrm{~cm}^{-1}$ that correspond to symmetric and asymmetric vibrations of $-\mathrm{CH}_{3}$ group and bond $\mathrm{C}-\mathrm{H}$, respectively, which is connected with a partial or complete removal of lignin from the bio-filler structure. The FTIR spectrum of the bio-filler, subjected to

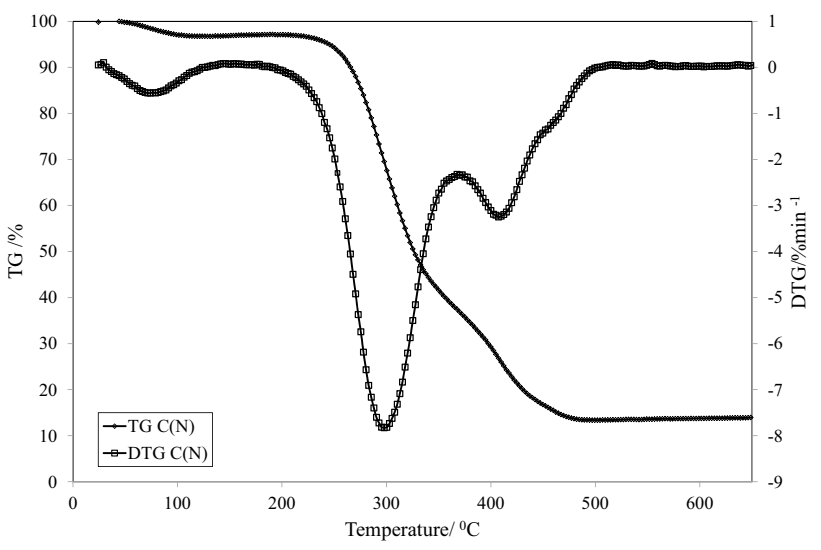

Fig. 4 TG and DTG curves of unmodified $\mathrm{C}(\mathrm{N})$ lignocellulose filler

hydrolysis and phosphorylation, distinctly shows an increase in the peak intensity at wavelength $899 \mathrm{~cm}^{-1}$. This signal indicates the appearance of phosphoric esters of cellulose (Fig. 3) [14, 19].

\section{Thermal Properties and Flammability}

The results of thermal analysis under air have shown that unmodified $\mathrm{C}(\mathrm{N})$ (Fig. 4) and hydrolytically modified $\mathrm{C}(\mathrm{OH})$ (Fig. 5) wheat straw are characterized by a distinct two-stage thermal decomposition.

The first loss of $\mathrm{C}(\mathrm{OH})$ mass, amounting to $4.3 \mathrm{wt} \%$, at $\Delta \mathrm{T}_{1}=50-150{ }^{\circ} \mathrm{C}$, with the maximum of mass loss at $\mathrm{T}=100{ }^{\circ} \mathrm{C}$ is connected with the evaporation of water physically and chemically bonded with the surface of bio-filler. The second stage of thermal decomposition at $\Delta \mathrm{T}_{2}=230-385{ }^{\circ} \mathrm{C}$ is connected first of all with its thermal decomposition (Fig. 5).

From the literature review it follows that the thermal decomposition of cellulose proceeds at $\Delta \mathrm{T}=260-350{ }^{\circ} \mathrm{C}$, while that of lignin at $\Delta \mathrm{T}=160-400{ }^{\circ} \mathrm{C}$, whereas the 


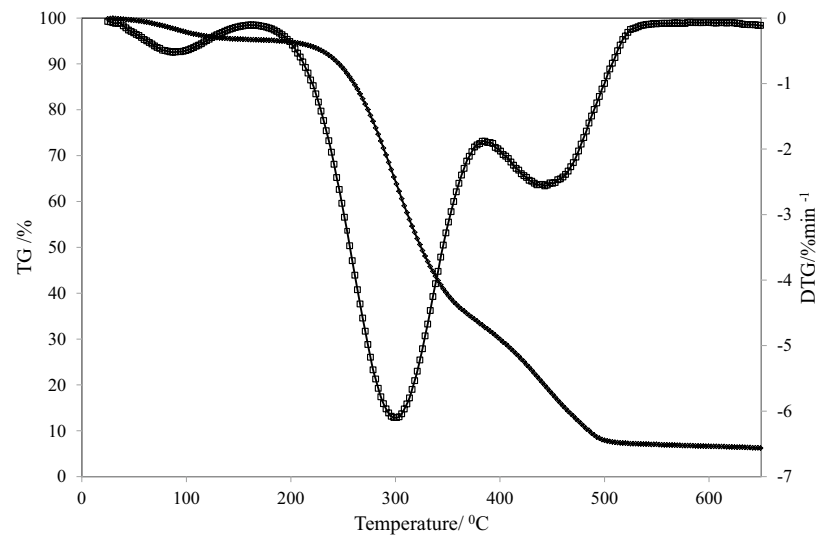

Fig. 5 TG and DTG curves of hydrolytically modified $\mathrm{C}(\mathrm{OH})$ lignocellulose filler

thermal decomposition of hemi-cellulose begins at a temperature above $180{ }^{\circ} \mathrm{C}[20]$.

Taking into account the small mass loss, amounting to $4.15 \mathrm{wt} \%$, recorded in the TG curve, at $\mathrm{T}=160-2300{ }^{\circ} \mathrm{C}$, as well as the high temperature of the end of the second stage of bio-filler thermal decomposition, one can conclude that despite of the alkalization process, the wheat straw tested, beside of cellulose, also contain a low quantity of lignin and hemi-cellulose.

In order to improve thermal parameters and resistance to the action of fire, the hydrolyzed wheat straw was subjected to phosphorylation with the use of di-potassium hydro phosphate $\left(\mathrm{K}_{2} \mathrm{HPO}_{4}\right)$.

The results of thermal analysis distinctly show that cellulose, constituting the main component of wheat straw, subjected to the phosphorylation process $\mathrm{C}(\mathrm{P})$ is characterized by a temperature higher by as many as $70{ }^{\circ} \mathrm{C}$ of the $5 \%$ loss of the sample weight in relation to hydrolyzed cellulose $\mathrm{C}(\mathrm{OH})$, and about fivefold increase in the residue after the thermal decomposition at $600{ }^{\circ} \mathrm{C}\left(\right.$ Parameter $\left.\mathrm{P}_{600}\right)$ (Fig. 6; Table 3).

The process of cellulose phosphorylation also advantageously influences the reduction in its flammability as indicated by both the parameter of mass loss rate, $\mathrm{dm} / \mathrm{dt}$, (Table 3) and the maximal heat release rate, $\mathrm{HRR}_{\max }$ (Fig. 7).

The test results obtained distinctly show that phosphorylated cellulose is characterized by $\mathrm{HRR}_{\max }$ lower by $61 \%$ in relation to that of the cellulose subjected only to alkaline hydrolysis (Fig. 7).

The improvement in thermal parameters and reduction in the flammability of phosphorylated cellulose in relation to hydrolytic cellulose are connected with the transformation of the hydroxyl groups of cellulose under the influence of phosphoric acid, formed by the hydrolytic dissociation of di-potassium hydro-phosphate, into cellulose esters of phosphoric acid. These esters, catalyzing the process of its

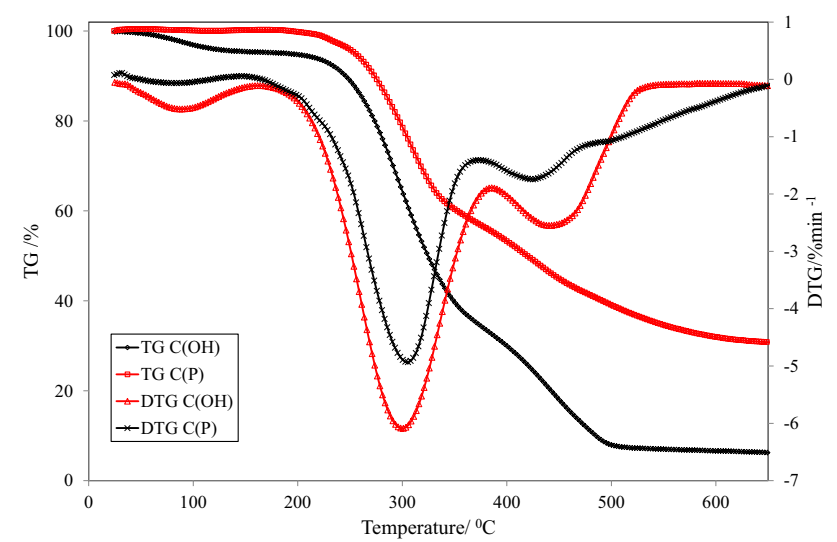

Fig. 6 TG and DTG curves of hydrolytically modified $\mathrm{C}(\mathrm{OH})$ and phosphorylated cellulose $\mathrm{C}(\mathrm{P})$

Table 3 Thermal analysis of unmodified cellulose $\mathrm{C}(\mathrm{N})$, hydrolyzed $\mathrm{C}(\mathrm{OH})$ and phosphorylated cellulose $\mathrm{C}(\mathrm{P})$

\begin{tabular}{lllr}
\hline Sample & $\mathrm{T}_{5}\left({ }^{\circ} \mathrm{C}\right)$ & $\mathrm{dm} / \mathrm{dt}\left(\% \times \mathrm{min}^{-1}\right)$ & $\mathrm{P}_{600}(\%)$ \\
\hline $\mathrm{C}(\mathrm{N})$ & 226 & 8.00 & 10.23 \\
$\mathrm{C}(\mathrm{OH})$ & 188 & 6.60 & 6.63 \\
$\mathrm{C}(\mathrm{P})$ & 255 & 5.08 & 31.89 \\
\hline
\end{tabular}

$\mathrm{T}_{5}-5 \%$ mass loss,

$\mathrm{dm} / \mathrm{dt}$-maximum rate of thermal decomposition of sample, $\% \mathrm{~min}^{-1}$, $\mathrm{P}_{600}$-residue after heating to $\mathrm{T}=600{ }^{\circ} \mathrm{C}$, wt $\%$

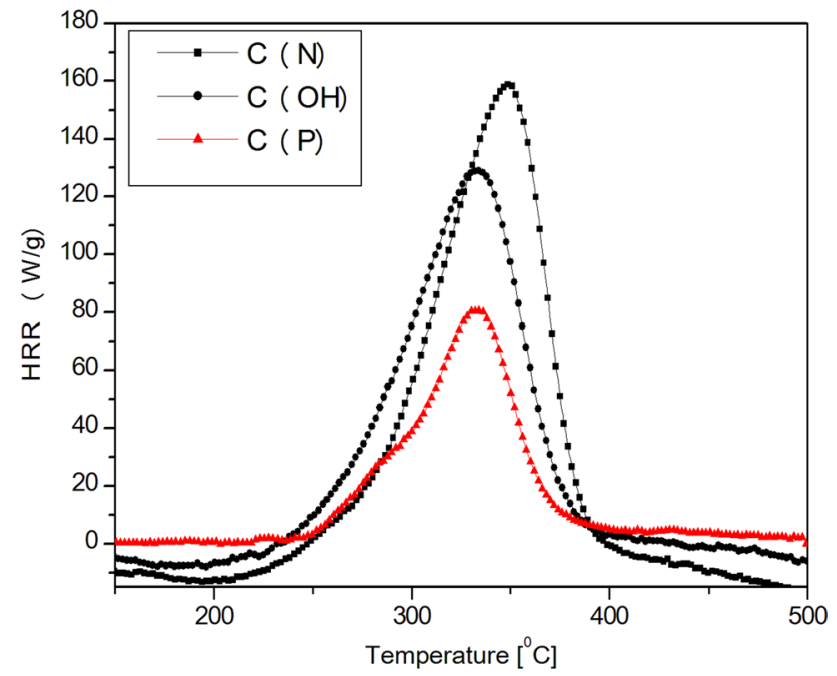

Fig. $7 \mathrm{HRR}_{\max }$ curves of unmodified cellulose $\mathrm{C}(\mathrm{N})$, hydrolytically modified $\mathrm{C}(\mathrm{OH})$ and phosphorylated cellulose $\mathrm{C}(\mathrm{P})$

dehydration, contribute to increasing the quantity of water vapor passing to flame, that directly influences the energetic balance of the combustion process and they also intensify the formation of a thermally stable carbonized residue that 
reduces the flow of mass and energy between sample and flame (Scheme 1) [14, 21].

It is also important that phosphorylation in the early stage of the combustion process reduces the transformation of cellulose into levoglucosan that is a precursor of flammable gaseous products of its destruction [20].

\section{Properties of Natural Rubber NR Composites}

\section{Cross-Link Density of NR Rubber Composites}

The comparable analysis of the results presented in Table 4 distinctly shows that both hydrolyzed cellulose $\mathrm{C}(\mathrm{OH})$ and phosphorylated cellulose $\mathrm{C}(\mathrm{P})$, does not advantageously influence the cross-linking process of natural rubber, as indicated by the lower cross-linking density of composites $\mathrm{NR}-\mathrm{C}(\mathrm{OH})$ and $\mathrm{NR}-\mathrm{C}(\mathrm{P})$ in relation to the initial sample NR. The incorporation of poly(ammonium phosphate) into the natural rubber matrix also does not exert ant influence on the increase in the cross-link density of natural rubber NR. On the other hand, an increase in the density of NR vulcanizates occurs as a result of the synergetic action of poly(ammonium phosphate) with: antimony trioxide $\mathrm{Sb}_{2} \mathrm{O}_{3}$, pentaerytrytol $\mathrm{PER}$, aluminum hydroxide $\mathrm{AlOH}$ and zinc borate $\mathrm{ZnB}$, respectively (Table 4).

\section{Thermal Stability and Flammability of NR Rubber Composites}

The results of thermal analysis have shown that the thermal decomposition of natural rubber cross-linked with sulfur proceeds at $\Delta \mathrm{T}=315-4600{ }^{\circ} \mathrm{C}$ (Fig. 8). From the literature review it follows that the destruction process of natural rubber has a complex character [22]. At first compounds with a high $\mathrm{H} / \mathrm{C}$ ratio are formed and then a bit slower cyclized, carbonized residue. The formation rate of volatile destruction products is considerably higher than the rate of oxygen diffusion to the reaction zone, and therefore the destruction processes of natural rubber proceed with oxygen deficiency. At the moment when the oxygen diffusion rate and the rate of rubber decomposition are similar, the solid, carbonized

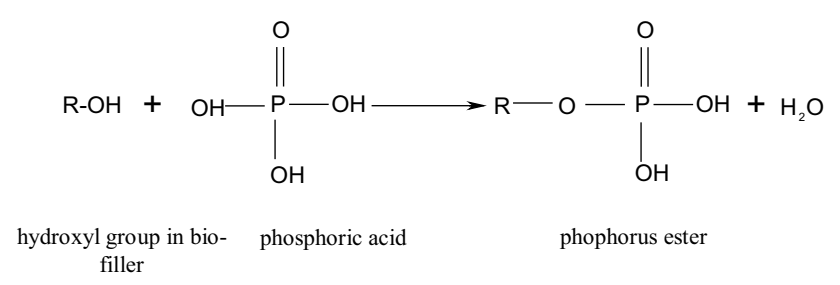

Scheme 1 Condensation of hydroxyl groups in bio-filler with phosphoric acids from decomposition $\mathrm{K}_{2} \mathrm{HPO}_{4}$. R-represents the main chain of the bio-filler, $\mathrm{OH}$ - hydroxyl group in the bio-filler [14]
Table 4 Influence of bio-filler, in the presence of appropriate flame retardants, on the cross-link density of NR rubber composites

\begin{tabular}{ll}
\hline Sample & $\alpha_{\mathrm{c}} \times 10^{-5}\left(\mathrm{~mol} \mathrm{~cm}^{-3}\right)$ \\
\hline $\mathrm{NR}$ & $1.81 \pm 0.08$ \\
$\mathrm{NR}-\mathrm{C}(\mathrm{OH})$ & $1.32 \pm 0.07$ \\
$\mathrm{NR}-\mathrm{C}(\mathrm{P})$ & $1.55 \pm 0.09$ \\
$\mathrm{NR}-\mathrm{C}(\mathrm{P})-\mathrm{APP}$ & $1.68 \pm 0.06$ \\
$\mathrm{NR}-\mathrm{C}(\mathrm{P})-\mathrm{APP}-\mathrm{PER}$ & $2.15 \pm 0.12$ \\
$\mathrm{NR}-\mathrm{C}(\mathrm{P})-\mathrm{APP}-\mathrm{Sb} \mathrm{O}_{3}$ & $1.89 \pm 0.03$ \\
$\mathrm{NR}-\mathrm{C}(\mathrm{P})-\mathrm{APP}-\mathrm{ATH}$ & $2.02 \pm 0.09$ \\
$\mathrm{NR}-\mathrm{C}(\mathrm{P})-\mathrm{APP}-\mathrm{ZB}$ & $1.87 \pm 0.02$ \\
\hline
\end{tabular}

$\alpha_{c}$ - cross-link density

residue begins to burn. The maximum rate of this process occurs at a temperature of $515{ }^{\circ} \mathrm{C}$ (DTG curve, Fig. 8). The incorporation of the bio-filler into the natural rubber matrix results in a decrease in its thermal stability expressed by both the coefficient of a $5 \%$ mass loss and the temperature of the thermal decomposition start (Fig. 8; Table 5). However, it should be clearly underline that the hydrolyzed $\mathrm{C}(\mathrm{OH})$, and especially the $\mathrm{C}(\mathrm{P})$ cellulose subjected to phosphorylation distinctly influences the reduction in the rubber thermal decomposition rate, $\mathrm{dm} / \mathrm{dt}$, and also the increase in the residue after its thermal decomposition, $\mathrm{Pw}$ and the residue at a temperature of $600{ }^{\circ} \mathrm{C}, \mathrm{P}_{600}$ (Fig. 8; Table 5).

A distinct increase in the values of parameters $\mathrm{P}_{\mathrm{w}}$ and $\mathrm{P}_{600}$ of the composite containing phosphorylated bio-filler $[\mathrm{NR}-\mathrm{C}(\mathrm{P})]$, compared to the untreated sample NR, is connected with the decomposition of the cellulose phosphoric esters. Catalyzing the dehydration of bio-filler, these esters intensify the cross-linking processes of the residue after the thermal decomposition.

Based on the results obtained by the method of cone calorimetry, it has been unexpectedly found that the hydrolyzed cellulose incorporated into the rubber matrix reduces its

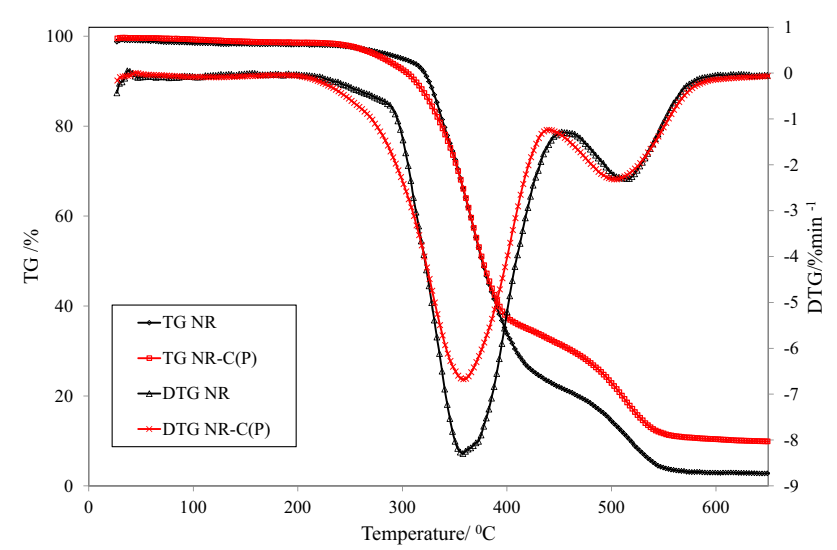

Fig. 8 TG and DTG curves of NR and NR-C(P) composites 
Table 5 Thermal analysis results of natural rubber NR composites

\begin{tabular}{llllllll}
\hline Sample & $\mathrm{T}_{5}\left({ }^{\circ} \mathrm{C}\right)$ & $\mathrm{T}_{50}\left({ }^{\circ} \mathrm{C}\right)$ & $\mathrm{T}_{\mathrm{RMAX}}\left({ }^{\circ} \mathrm{C}\right)$ & $\mathrm{dm} / \mathrm{dt}\left(\% \mathrm{~min}^{-1}\right)$ & $\mathrm{Pw}(\%)$ & $\mathrm{Ts}\left({ }^{\circ} \mathrm{C}\right)$ & $\mathrm{P}_{600}(\%)$ \\
\hline $\mathrm{NR}$ & 300 & 376 & 365 & 9.01 & 21.97 & 515 & 2.95 \\
$\mathrm{NR}-\mathrm{C}(\mathrm{OH})$ & 277 & 371 & 355 & 8.25 & 26.39 & 510 & 4.69 \\
$\mathrm{NR}-\mathrm{C}(\mathrm{P})$ & 289 & 377 & 363 & 7.02 & 32.62 & 510 & 10.37 \\
$\mathrm{NR}-\mathrm{C}(\mathrm{P})-\mathrm{APP}$ & 282 & 415 & 370 & 4.91 & 39.24 & 545 & 33.31 \\
$\mathrm{NR}-\mathrm{C}(\mathrm{P})-\mathrm{APP}-\mathrm{PER}$ & 262 & 408 & 364 & 4.71 & 41.14 & 536 & 31.53 \\
$\mathrm{NR}-\mathrm{C}(\mathrm{P})-\mathrm{APP}-\mathrm{Sb} \mathrm{O}_{3}$ & 286 & 420 & 369 & 4.58 & 42.58 & 551 & 34.09 \\
$\mathrm{NR}-\mathrm{C}(\mathrm{P})-\mathrm{APP}-\mathrm{ATH}$ & 291 & 569 & 355 & 3.09 & 57.23 & 547 & 47.80 \\
$\mathrm{NR}-\mathrm{C}(\mathrm{P})-\mathrm{APP}-\mathrm{ZB}$ & 280 & 430 & 362 & 4.44 & 48.35 & 528 & 32.57 \\
\hline
\end{tabular}

$\mathrm{T}_{5}$ and $\mathrm{T}_{50}$-temperature of sample 5 and $50 \%$ mass loss, respectively,

$\mathrm{T}_{\mathrm{RMAX}}$ - temperature of maximum rate of thermal decomposition of tested vulcanizates,

Pw-residue after the thermal decomposition of composites,

Ts-temperature of residue burning after the thermal decomposition of composites

Table 6 The flammability data of NR rubber composites obtained by the cone calorimeter method

\begin{tabular}{|c|c|c|c|c|c|c|c|}
\hline Sample & TTI (s) & THR $\left(\mathrm{MJ} \mathrm{m}^{-2}\right)$ & $\operatorname{HRR}\left(\mathrm{kW} \mathrm{m}^{-2}\right)$ & 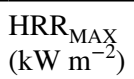 & $\mathrm{EHC}\left(\mathrm{MJ} \mathrm{kg}^{-1}\right)$ & $\begin{array}{l}\mathrm{EHC}_{\mathrm{MAX}} \\
\left(\mathrm{MJ} \mathrm{kg}^{-1}\right)\end{array}$ & $\operatorname{MLR}\left(\mathrm{g} \mathrm{m}^{-2} \mathrm{~s}^{-1}\right)$ \\
\hline NR & 52 & 40.1 & 198.4 & 511.19 & 27.06 & 74.58 & 19.62 \\
\hline $\mathrm{NR}-\mathrm{C}(\mathrm{OH})$ & 40 & 38.5 & 141.6 & 413.02 & 28.12 & 78.41 & 13.60 \\
\hline $\mathrm{NR}-\mathrm{C}(\mathrm{P})$ & 37 & 38.2 & 173.1 & 376.45 & 26.90 & 74.65 & 14.39 \\
\hline $\mathrm{NR}-\mathrm{C}(\mathrm{P})-\mathrm{APP}$ & 43 & 29.6 & 180.25 & 340.56 & 26.26 & 62.09 & 16.56 \\
\hline NR-C(P)-APP-PER & 60 & 24.7 & 195.18 & 335.37 & 19.44 & 75.68 & 16.07 \\
\hline $\mathrm{NR}-\mathrm{C}(\mathrm{P})-\mathrm{APP}-\mathrm{Sb}_{2} \mathrm{O}_{3}$ & 49 & 38.3 & 147.1 & 352.3 & 28.93 & 76.37 & 13.29 \\
\hline NR-C(P)-APP-ATH & 59 & 19.3 & 99.81 & 193.78 & 14.92 & 74.01 & 12.06 \\
\hline $\mathrm{NR}-\mathrm{C}(\mathrm{P})-\mathrm{APP}-\mathrm{ZB}$ & 46 & 27.2 & 150.83 & 273.89 & 21.63 & 77.68 & 11.68 \\
\hline
\end{tabular}

$T T I$ time to ignition, $T H R$ total heat release, $H R R$ heat release rate, $E H C_{M A X}$ max effective heat of combustion, $H R R_{M A X}$ max heat release rate, $E H C$ effective heat of combustion, $M L R$ mass loss rate

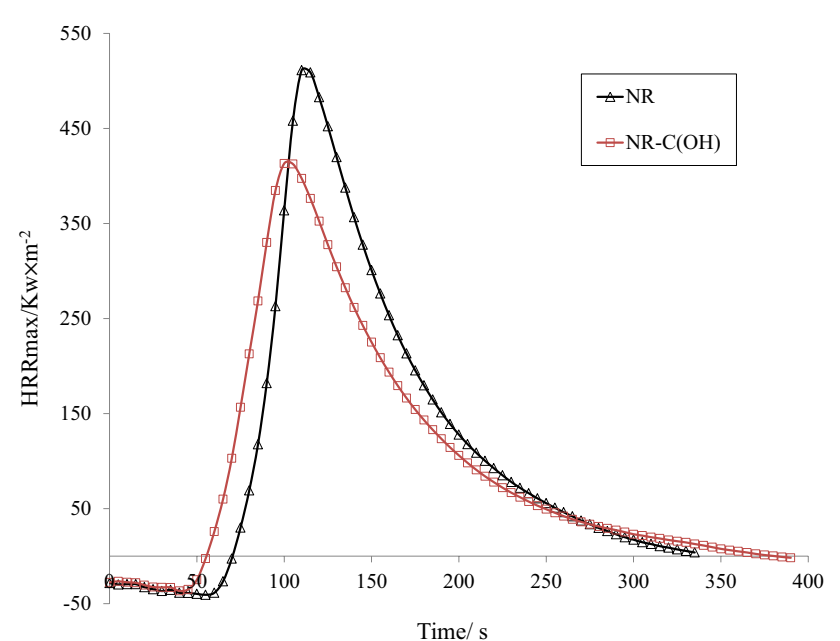

Fig. $9 \mathrm{HRR}_{\max }$ curves of $\mathrm{NR}$ and $\mathrm{NR}-\mathrm{C}(\mathrm{OH})$ composites

flammability (Table 6). The value of parameter $\mathrm{HRR}_{\max }$ of composite $\mathrm{NR}-\mathrm{C}(\mathrm{OH})$ was reduced by $19.2 \%$ in relation to the initial vulcanizate NR (Fig. 9).
From the literature review it follows that the crystalline structure of hydrolyzed cellulose (cellulose II) is more thermally stable, compared to unmodified cellulose (cellulose I), which together with the fibrillation of cellulose fibers, resulting in the increase in their orientation, contributes to decreasing the quantity of oxygen diffusing onto the surface of fibers, and consequently results in a reduction in the rate of their thermo-oxidative decomposition, as confirmed by the parameter of mass loss rate MLR (Table 5; Fig. 10).

A radical decrease in the flammability of the natural rubber composites was obtained with the use of phosphorus compounds. The results obtained by the method of cone calorimetry distinctly show a decrease in parameters HRR, $\mathrm{HRR}_{\max }$ and EHC as a result of the modification of alkali cellulose with phosphorus compounds. A significant reduction in parameter MLR that is of paramount importance from the point of view of fire propagation and connected with it parameter of mass loss rate, $\mathrm{dm} / \mathrm{dt}$, has not been obtained until the additive flame-retardant compound in the form ammonium polyphosphate APP was incorporated into the natural rubber matrix (Table 6). 


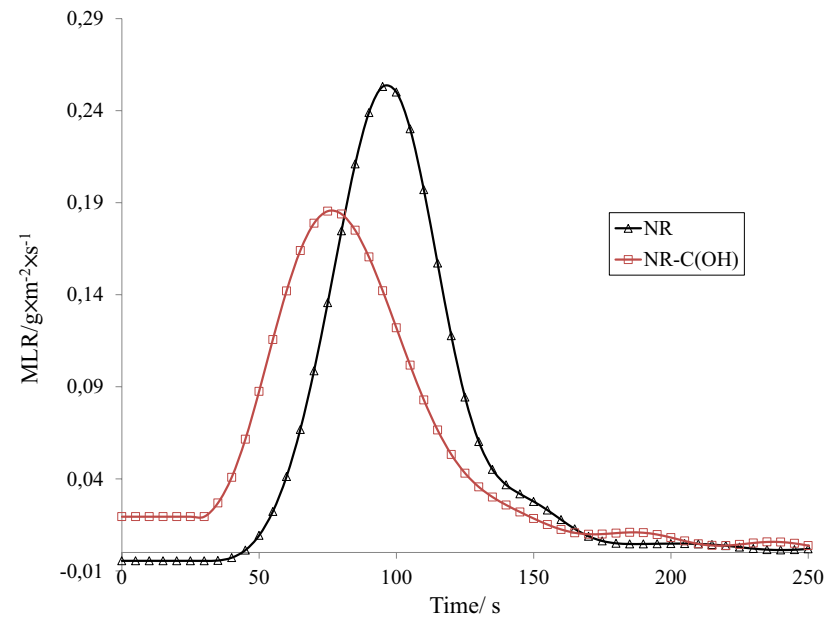

Fig. 10 MLR curves of NR and NR-C(OH) composites

Polyphosphoric acid formed by the thermal degradation of APP, reacting with hydroxyl groups of alkali cellulose forms esters responsible for creating a homogeneous carbon layer that reduces the flow of mass and energy between the sample and flame, as indicated by an increase in the parameter of combustion residue Pw (Table 5). Water and ammonia formed by the decomposition of APP, diluting the gaseous destruction products of burning composite, likewise phosphoric radicals fulfilling the function of the scavenger of highly energetic hydrogen and hydroxyl radicals, reduce the energetic balance of the combustion process [23].

An increase in the efficiency of APP in the formation of the isolating carbon layer can be obtained in the presence of systems intensifying the carbonization process, i.e. polyols, e.g. pentaerithritole [24]. However, the test results obtained show that pentaerithritol does not significantly increase the residue after the thermal decomposition, $\mathrm{PW}$, of sample NR-C(P)-APP-PER, in relation to composite $\mathrm{NR}-\mathrm{C}(\mathrm{P})-\mathrm{APP}$, and consequently there is no distinct impact of PER on reducing the flammability of NR composite containing APP. This indicates that the quantity of bio-filler in the polymeric matrix, with the assumed quantity of APP, is optimal from the point of view of the efficiency of the esterification reaction (Table 6).

The reduction in the flammability of natural rubber composite, expressed by parameters THR, HRR, $\mathrm{HRR}_{\max }$, EHC and MLR, occurs as a result of the synergetic action of APP and antimony trioxide $\left(\mathrm{Sb}_{2} \mathrm{O}_{3}\right)$ (Table 6). Antimony trioxide incorporated into the NR-C(P)-APP composite matrix does not influence the thermo-oxidative degradation of the vulcanizate, but reacting with APP contributes to increasing the rubber cross-link density (Table 3; Fig. 11). It also increases the cross-linking degree of the boundary layer, as indicated by the increased value of the parameter of the residue after the sample thermal decomposition, $\mathrm{Pw}$ and the residue after the decomposition at $\mathrm{T}=600{ }^{\circ} \mathrm{C}$ (parameter $\mathrm{P}_{600}$ ) of vulcanizate NR-C(P)-APP-Sb ${ }_{2} \mathrm{O}_{3}$ compared to NR-C(P)-APP (Table 5; Fig. 11). The uniform isolating boundary layer effectively reduces the transport of mass and energy between sample and flame.

A radical reduction in the flammability of NR-C(P) composite was obtained as a result of synergetic action of APP with aluminum hydroxide (Table 6). The flame-retardant effect of aluminum hydroxide, consisting in liberating water vapor, during its decomposition, diluting the flammable products of polymer decomposition, and forming a thermally stable ceramic layer as a barrier for heat and mass transport, is well known. However, the effectiveness of the ATH action is satisfactory only with a degree of filling, which negatively influence the mechanical properties of the composites containing this filler [26].

ATH is connected with a chemical reaction proceeding at a temperature below $400{ }^{\circ} \mathrm{C}$ between ammonium group of APP and hydroxyl group of ATH, resulting in the formation of aluminum phosphate that stabilizes the boundary layer of the combusting composite. At the same time water vapor

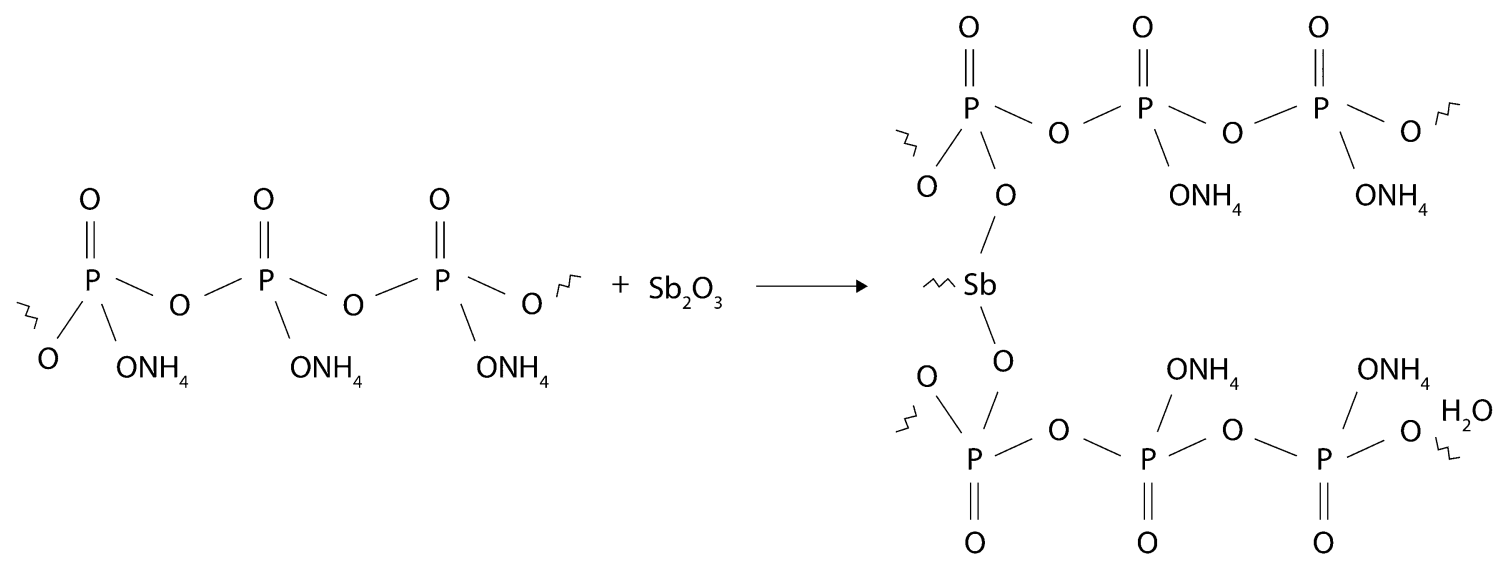

Fig. 11 Schematic illustration of the reaction between $\mathrm{APP}$ and $\mathrm{Sb}_{2} \mathrm{O}_{3}$ in the rubber matrix [25] 
and ammonia are released and dilute the gaseous products of the rubber thermal decomposition, decreasing the energetic balance of its combustion process. So, the synergetic flame-retardant action of the APP-ATH system consists in forming an isolating cross-linked boundary layer containing aluminum phosphate (Table 4). At the same time basic ATH makes it possible to transfer protons, which facilitates the formation of gaseous decomposition products, i.e. water vapor and ammonia (Fig. 12) [27].

However, it should be also mentioned that from the literature review it follows that at a temperature above $400{ }^{\circ} \mathrm{C}$, there may proceed a reaction between APP and ATH resulting in the formation of crystalline aluminum ortho-phosphate that decreasing the homogeneity of the boundary layer, negatively influence the flame-retardant action of the APP-ATH system [28].

The synergetic action of the system APP-zinc borate (ZB) resulting in the reduction in the flammability of the NR-CP composite is connected not only with the formation of an isolating glassy boundary layer, but also with lowering the temperature of its formation. Zinc borate forms a glassy protective layer already at a temperature above $300{ }^{\circ} \mathrm{C}$, and at the same time it increases the effectiveness of the esterification reactions proceeding with APP, as a pore-forming agent [11].

\section{Mechanical Properties of NR Composites}

\section{Static Mechanical Properties}

Mechanical properties composites of NR rubber are presented in the Table 7. Incorporation alkaline cellulose to
Table 7 Static mechanical properties of NR composites

\begin{tabular}{llll}
\hline Sample & $\mathrm{SE}_{300}(\mathrm{MPa})$ & $\mathrm{T}_{\mathrm{S}}(\mathrm{MPa})$ & $\mathrm{Eb}(\%)$ \\
\hline $\mathrm{NR}$ & $1.59 \pm 0.04$ & $9.13 \pm 0.74$ & $655 \pm 21$ \\
$\mathrm{NR}-\mathrm{C}(\mathrm{OH})$ & $2.22 \pm 0.23$ & $7.92 \pm 0.59$ & $551 \pm 15$ \\
$\mathrm{NR}-\mathrm{C}(\mathrm{P})$ & $2.34 \pm 0.03$ & $8.82 \pm 0.27$ & $582 \pm 10$ \\
$\mathrm{NR}-\mathrm{C}(\mathrm{P})-\mathrm{APP}$ & $2.52 \pm 0.23$ & $6.11 \pm 0.39$ & $522 \pm 27$ \\
$\mathrm{NR}-\mathrm{C}(\mathrm{P})-\mathrm{APP}-\mathrm{PER}$ & $2.99 \pm 0.07$ & $6.35 \pm 0.16$ & $486 \pm 7$ \\
$\mathrm{NR}-\mathrm{C}(\mathrm{P})-\mathrm{APP}-\mathrm{Sb}_{2} \mathrm{O}_{3}$ & $2.36 \pm 0.07$ & $4.57 \pm 0.37$ & $459 \pm 11$ \\
$\mathrm{NR}-\mathrm{C}(\mathrm{P})-\mathrm{APP}-\mathrm{ATH}$ & $2.58 \pm 0.15$ & $6.67 \pm 0.28$ & $532 \pm 15$ \\
$\mathrm{NR}-\mathrm{C}(\mathrm{P})-\mathrm{APP}-\mathrm{ZB}$ & $2.79 \pm 0.05$ & $6.23 \pm 0.21$ & $491 \pm 11$ \\
\hline
\end{tabular}

$\mathrm{SE}_{300}$ - stress at $300 \%$ elongation

$\mathrm{E}_{\mathrm{b}}$ - elongation at break

Ts-tensile strength

the rubber matrix, in a little extent decrease tensile strength parameter TS investigated composites, in comparison with the reference sample NR. The addition of $30 \mathrm{phr}$. of APP decreasing the value of TS parameter to $6 \mathrm{MPa}$ (Table 7). Furthermore, the use of other flame retardants together with APP doesn't have a positive effect on the mechanical properties e.g. (tensile strength and elongation at break) of NR composites. Cellulose and flame retardants incorporated to a polymer matrix acting as a barrier, decreasing mobility of rubber chains and in consequence worsening mechanical properties of NR composites. Incorporated to the NR rubber fillers (bio-filler and flame retardant) increase its stiffness and hardness (Fig. 13).<smiles></smiles><smiles>C1CC1</smiles>

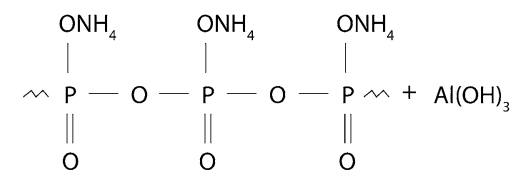<smiles></smiles>

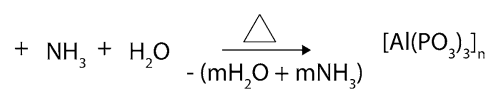<smiles>CP(=O)(O)OP(C)(=O)OP(C)(=O)ON</smiles><smiles>C[14C](=O)P(=O)(O)OP(=O)(ON)OP(C)(=O)O</smiles><smiles>N[P+](=O)OP(N)(=O)OP(=O)(O[18OH])O[13C](=O)O</smiles>

Fig. 12 Reactions between ATH and APP at elevated temperature in the NR composite matrix 


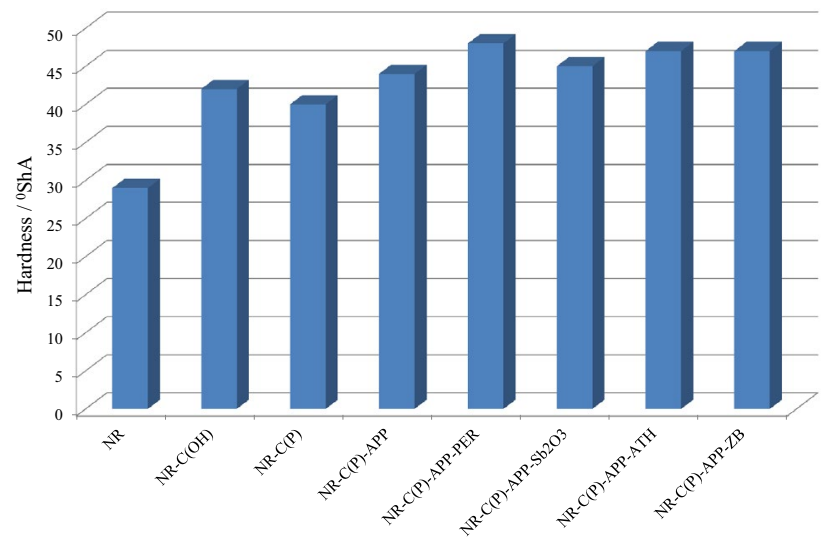

Fig. 13 Hardness of NR composites

\section{Dynamic Mechanical Properties}

The properties of the elastomers are nonlinear, the dynamic modules are dependent on temperature, deformation and frequency. The dynamic modulus of rubber increases with addition of filler. Filler-filler interaction contributes to the strain dependence of the modulus. The modulus value decreases with increasing strain, the so called Payne effect $\left(\Delta \mathrm{G}^{\prime}\right)$, which is due to partially breakdown of the filler network. The modulus is a combination of filler interactions in the crosslinked rubber network contribution and a hydrodynamic effect of the filler [29]. The aim of determination of the filler structure in the matrix, the dynamic mechanical analysis of the filled composites were done with a wide range of deformation at room temperature.

The maximum loss modulus was at the deformation where the decrease of the storage module was the fastest, so the mechanical energy dissipation is related to the destruction of physical filler-filler and filler-elastomer interactions.

The value of $\Delta \mathrm{G}^{\prime}$ is probably related to the formation of theirs own structure by the filler "network" in the elastomer. Presented data indicate that of $\mathrm{C}(\mathrm{OH})$ increased $\Delta \mathrm{G}^{\prime}$ in elastic modulus in comparison with composite filled with $\mathrm{C}(\mathrm{P})$ (Table 8). This effect can be related to a tendency of agglomeration of the filler particles modified only by $\mathrm{NaOH}$. The incorporation of flame retardant together with $\mathrm{C}(\mathrm{P})$ resulted in increase (decrement in elastic modulus) in $\Delta \mathrm{G}^{\prime}$ values, it can be explained by the possibility of creating "an additional structure" in the polymer matrix and particles agglomeration.

\section{Conclusion}

The improvement in thermal parameters and reduction in the flammability of phosphorylated cellulose in relation to hydrolytic cellulose are connected with the transformation
Table 8 The Payne effect $\left(\Delta \mathrm{G}^{\prime}\right)$ and maximum loss modulus $\mathrm{G}^{\prime \prime}$ values of the elastomer composites

\begin{tabular}{lll}
\hline Sample & $\Delta \mathrm{G}^{\prime}(\mathrm{MPa})$ & $\mathrm{G}^{\prime \prime m a x}(\mathrm{MPa})$ \\
\hline NR-C $(\mathrm{OH})$ & 0.26 & 0.03 \\
$\mathrm{NR}-\mathrm{C}(\mathrm{P})$ & 0.12 & 0.03 \\
NR-C(P)-APP & 0.60 & 0.09 \\
NR-C(P)-APP-PER & 0.52 & 0.07 \\
NR-C(P)-APP-Sb ${ }_{2} \mathrm{O}_{3}$ & 0.39 & 0.13 \\
NR-C(P)-APP-ATH & 1.12 & 0.24 \\
NR-C(P)-APP-ZB & 0.63 & 0.12 \\
\hline
\end{tabular}

$\Delta \mathrm{G}^{\prime}$ - decrement in elastic modulus

$\mathrm{G}^{\prime \prime}$-loss modulus

of the hydroxyl groups of cellulose under the influence of phosphoric acid, formed by the hydrolytic dissociation of di-potassium hydro-phosphate, into cellulose esters of phosphoric acid. These esters, catalyzing the process of its dehydration, contribute to increasing the quantity of water vapor passing to flame, that directly influences the energetic balance of the combustion process and they also intensify the formation of a thermally stable carbonized residue that reduces the flow of mass and energy between sample and flame.

A radical decrease in the flammability of the natural rubber composites was obtained as a result of synergetic action of additive poly(ammonium phosphate) with: pentaerytrytol, antimony trioxide, aluminum hydroxide and zinc borate. Sample NR-C(P)-APP-ATH is characterized the lowest flammability among all tested samples. Restriction flammability of NR-C $(\mathrm{P})$ composite containing mixture APP and ATH is connected with a chemical reaction proceeding at a temperature below $400{ }^{\circ} \mathrm{C}$ between ammonium group of APP and hydroxyl group of ATH, resulting in the formation of aluminum phosphate that stabilizes the boundary layer of the combusting composite.

Mechanical properties of NR composites in the presence of bio-fillers $\mathrm{C}(\mathrm{OH})$ or $\mathrm{C}(\mathrm{P})$ are to a little extent worse than NR rubber vulcanizate.

Cellulose and flame retardants incorporated to a polymer matrix acting as a barrier, decreasing mobility of rubber chains and in consequence worsening mechanical properties of NR composites. On the other hands fillers (bio-filler and flame retardant) in the NR matrix are increasing the stiffness and hardness of NR composite.

Hydrolytic cellulose $\mathrm{C}(\mathrm{OH})$ in NR matrix increased $\Delta \mathrm{G}^{\prime}$ in elastic modulus in comparison with composite filled with $\mathrm{C}(\mathrm{P})$. This effect can be related to a tendency of agglomeration of the filler particles modified only by $\mathrm{NaOH}$. The incorporation of flame retardant together with $\mathrm{C}(\mathrm{P})$ resulted in increase (decrement in elastic modulus) in $\Delta \mathrm{G}^{\prime}$ values, it can be explained by the possibility of creating "an 
additional structure" in the polymer matrix and particles agglomeration.

Open Access This article is distributed under the terms of the Creative Commons Attribution 4.0 International License (http://creativecommons.org/licenses/by/4.0/), which permits unrestricted use, distribution, and reproduction in any medium, provided you give appropriate credit to the original author(s) and the source, provide a link to the Creative Commons license, and indicate if changes were made.

\section{References}

1. Van de Weyenberg I, Truong TC, Vangrimde B, Verpoest I (2006) Compos A 37:1368-1376

2. Liu X, Wu Z, Han Y, Han L (2017) Energy 133:299-305

3. Chen JI, Sun L, Negulescu IJ, Xu B (2017) Biomass Bioenergy 101:1-8

4. Fengel D, Wegener G (1983) Cellulose. Wood: chemistry, ultrastructure, reactions. De Gruyter, Berlin, pp 66-105

5. Gassan J, Bledzki AK (1999) Compos Sci Technol 59(9):1303-1309

6. Mngomezulu ME, John MJ, Jacobs V, Luyt AS (2014) Carbohydr Polym 111:149-182

7. Kozlowski R, Wladyka-Przybylak M (2008) Polym Adv Technol 19:449-453

8. Kozlowski R, Wladyka-Przybylak M (2001) Natural polymers, wood and lignocellulosic materials. In: Horrocks AR, Price D (eds) Fire retardant materials, Woodhead Publishing, Cambridge, pp 293-317

9. Grexa O, Lubke H (2001) Polym Degrad Stab 74:427-432

10. Grexa O, Poutch F, Manikova D, Martuonova H, Bartekova A (2003) Polym Degrad Stab 82:373-377
11. Lazko J, Landery N, Laoutid F, Dangreau L, Huguet MH, Talon O (2013) Polym Degrad Stab 98:1043-1051

12. Kandola BK, Horrocks AR (2000) Fire Mater 24:265-275

13. Flambard X, Bourbigot S, Kozlowski R, Muzyczek M, Mieleniak B, Ferreira M et al (2005) Polym Degrad Stab 88:98-105

14. Suardana NPG, Ku MS, Lim JK (2011) Mater Des 32(4):1990-1994

15. Shumao L, Jie R, Hua Y, Tao Y, Weizhong Y (2010) Polym Int 59(2):242-248

16. Flory PJ, Rehner J (1943) J Chem Phys 11:512-520

17. Flory PJ (1950) J Chem Phys 18:108-111

18. Rybiński P, Janowska G (2014) J Therm Anal Calorim 117:377-386

19. Liodakis S, Fetsis IK, Agiovlasitis IP (2009) J Therm Anal Calorim 98:285-291

20. Chapple S, Anandjiwala R (2010) J Thermoplast Compos Mater 23:871-893

21. Gaon S, Sun G (2007) Polym Degrad Stab 92:968-974

22. Janowska G (1998) Scientific books of Technical University of Lodz. No 801

23. Schartel B (2010) Materials 3:4710-4745

24. Bar M, Alagirusamy R, Das A (2015) Fibers Polym 16(4):705-717

25. Li N, Xia Y, Mao Z, Wang L, Guan Y, Zheng A (2012) Polym Degrad Stab 97:1737-1744

26. Rybiński P, Żukowski W, Bradło D (2016) J Therm Anal Calorim 125:1373-1386

27. Khali P, Tshai KY, Hui D, Kong I (2017) Compos B 114:101-110

28. Castrovinci A, Camino G, Drevelle C, Duquesne S, Magniez G, Vouters M (2005) Eur Polym J 41:2023-2033

29. Wang J, Hamed GR, Umetsu K, Roland CM (2005) Rubber Chem Technol 78:76-83 